\title{
Release of lamellar bodies from alveolar type 2 cells
}

\author{
N F JOHNSON \\ From the Medical Research Council Pneumoconiosis Unit, Llandough Hospital, \\ Penarth, South Glamorgan, Wales
}

ABSTRACT The release of lamellar bodies from rat alveolar type 2 cells has been studied during $12 \mathrm{hr}$ dark/12hr light cycle. A proportion of the type 2 cell population was ultrastructurally abnorma The cellular changes formed a spectrum ranging from mild to severe, culminating in rupture of the cell and release of its contents into the alveolar air space. The majority of aberrant cells were observed in animals killed during the dark period. A holocrine secretory mechanism is suggested for the release of lamellar bodies containing the surface active phospholipids of the alveolar lining The release of lamellar material by a process of exocytosis was also observed, but only rarely, i spite of the numerous lamellar bodies seen in each cell cross-section.

The type 2 alveolar cell, or granular pneumocyte, is well established in the literature as the source of the surface active phospholipids in the alveolar lining. ${ }^{1-4} \mathrm{~A}$ characteristic of the type 2 cell is the numerous lamellar cytoplasmic inclusions which are considered to be the storage form of the surfactant. The lamellar bodies have been shown to be discharged by a process of exocytosis into the alveolar lining fluid. ${ }^{5-8}$ During investigations into normal lung ultrastructure it was puzzling that, given the large number of lamellar bodies in each cell, relatively few such bodies were found in the process of releasing their contents into the alveolar air space. The possibility exists that shedding of the lamellar bodies occurs at a time when investigators usually do not remove lungs, for example, at night. To examine this problem lungs of SPF rats have been examined at different times of the diurnal light dark cycle. During the course of this investigation it was apparent that a process of exocytosis may not be the only route for the release of lamellar bodies.

\section{Methods}

Twenty-four 1-year-old female SPF Fischer rats, weighing $200-300 \mathrm{~g}$, were used in this investigation. Before killing for histology, the animals were maintained on a $12 \mathrm{hr}$ light, $12 \mathrm{hr}$ dark cycle for three months (lights on at 0700, off at 1900). During this period the animals were kept on a

Address for reprint requests: Dr NF Johnson, MRC Pneumoconiosis Unit, Llandough Hospital, Penarth, S Glamorgan, Wales CF6 1XW. standard rat diet and water ad libitum. Thळ animals were killed in groups of two at two hourly intervals (on the even hours) with chloro form, and the left lung removed. Before fixation a 1-2mm thick slice of tissue was taken from the region of the midline of the lung in an antero posterior direction. The primary fixative used was $3 \%$ glutaraldehyde buffered with Sorensen's phosphate buffer $(\mathrm{pH} 7 \cdot 2-7 \cdot 4)$. The remaining lun tissue was sliced and stored in fixative. The mid portion of the central slice was cut into $1-2 \mathrm{mn}$ square blocks and processed conventionally fo, electron microscopy. In addition, two malês Sprague Dawley rats, which were maintaine $\Phi$. under routine animal house conditions, were per 8 fused during the afternoon with glutaraldehyde fixative using a previously described procedures and the left lung removed. Tissue was taken from a similar location as above and processed cono ventionally for electron microscopy. Sections $60 \overline{\bar{N}}$ $90 \mathrm{~nm}$ thick were cut at $25 \mu \mathrm{m}$ intervals and the number of lamellar inclusion bodies were counted in 20 nucleated cell cross-sections in all animals This was in addition to an ultrastructural examo ination of the normal lung tissue.

\section{Results}

The majority of alveolar type 2 cells were ultrae structurally normal (fig 1), and their appearance was similar to previously published descriptions. ${ }^{5}{ }^{\circ}$ However, a proportion of the type 2 cells werg of abnormal appearance. The degree of degeners ation in these aberrant cells varied considerablo 
from mildly to severely affected. The changes in these cells could be placed into a sequence which may represent events leading to cell death and release of cellular contents into the alveolar air space (figs 2-4). The initial alteration involved rounding of the mitochondria and limited focal separation of the membranes of the nuclear envelope. The mitochondrial rounding became more marked with an increase in the density of the matrix and ballooning of the cristae. The separation of the nuclear envelope membranes was also more pronounced and widespread with diverticula extending into the cytoplasm. In addition, the cytoplasm was more electron translucent and the rough endoplasmic reticulum was in the form of small rounded vesicles. This stage was followed by the rupture of the cell membrane facing the alveolar air space and extrusion of the cellular contents.

In all animals studied cell debris was observed in the alveoli. This debris consisted of cell membranes, nuclei, degenerate mitochondria, lamellar bodies, swollen vesicles, and tubular and lattice myelin (figs 3, 5). Much of this material was similar to the cell constituents which were seen extruding from the ruptured type 2 cells. The remnants of the cell membranes took on a variety of forms from circular (1-8 $\mu$ in diameter) to angular (fig 6). The original membrane surface facing the cytoplasm appeared to be on the outside facing the alveolar air space as it was this surface of the membrane profiles that was associated with the cellular remnants. As a result of the size of many of these profiles, they were frequently identified in $1 \mu \mathrm{m}$ sections stained with toluidine blue. Many of the alveolar macrophages contained secondary lysosomes and a few pos-

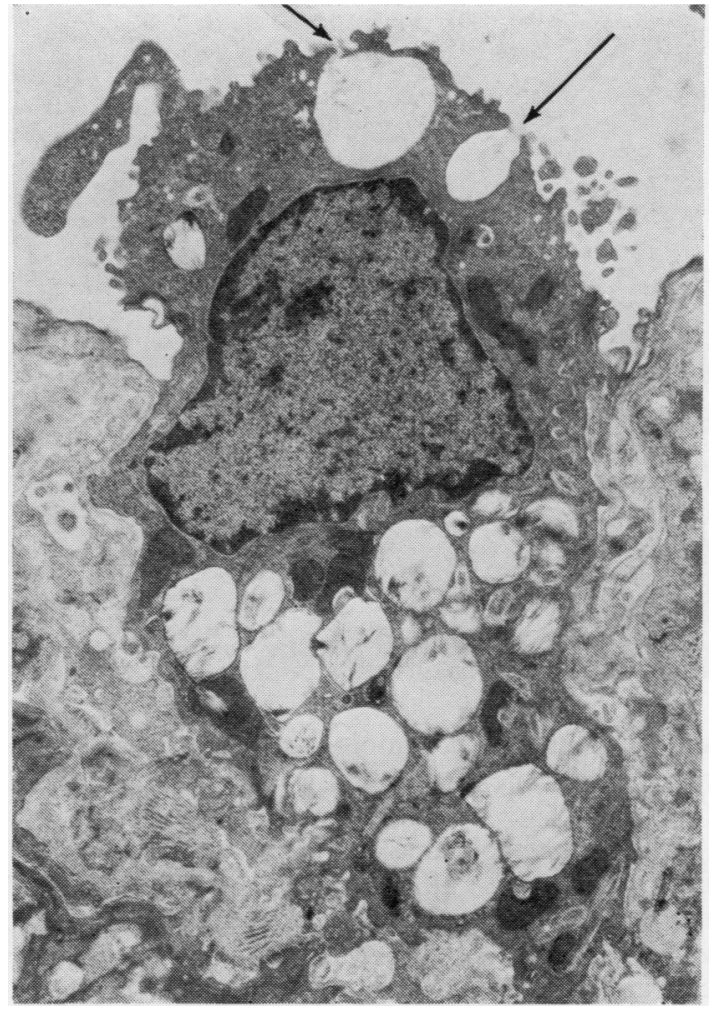

Fig 1 Electron micrograph of an ultrastructurally normal type 2 cell. This cell was one of the four nucleated cell cross-sections out of 480 studied which showed lamellar bodies open to the alveolar air space (arrow). The lamellar structure of the inclusion bodies is poorly preserved as a result of the conventional tissue processing techniques used. Original magnification $\times 10000$.

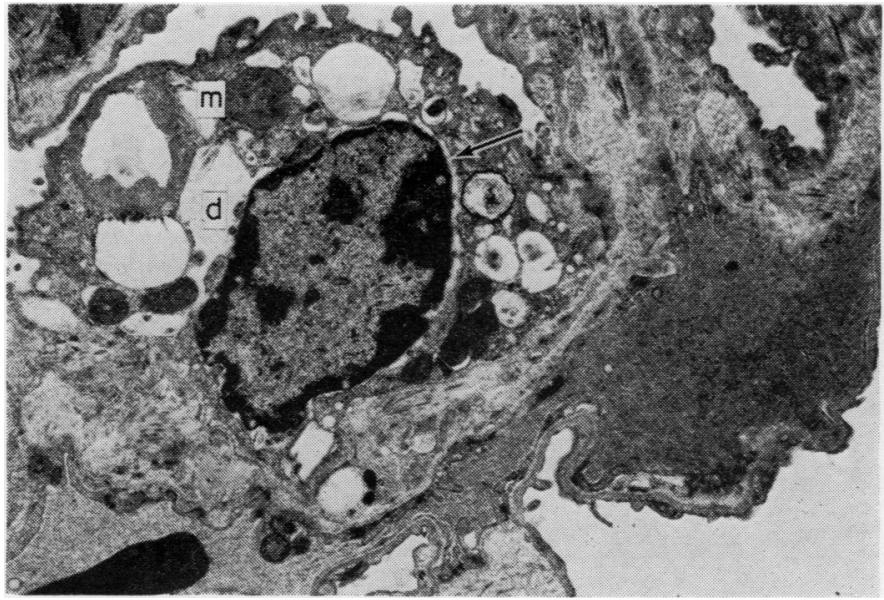

Fig 2 Electron micrograph of an aberrant type 2 cell. The mitochondria are rounded with an electron dense matrix $(m)$, the membranes of the nuclear envelope are separated (arrow), and a diverticulum (d) extends into the cytoplasm. Original magnification $\times 10000$. 


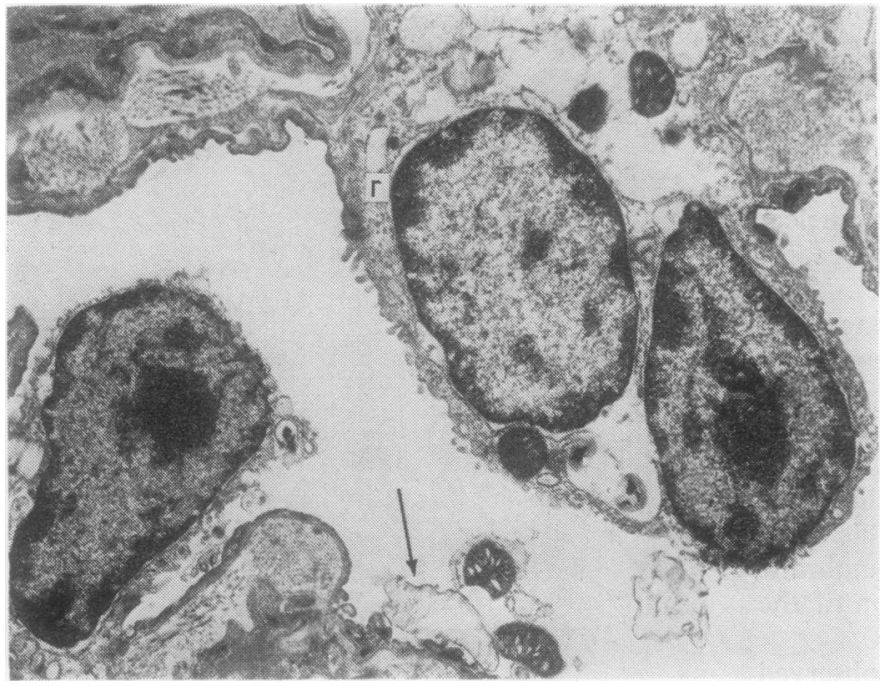

Fig 3 Electron micrograph of ruptured type 2 cells. The apical cell membranes. are ruptured and the cytoplasm is more translucent than normal and contains swollen vesicles of rough endoplasmic reticulum $(r)$. The air space contains cell debris including degenerate mitochondria and a lamellar body (arrow). Original magnification $\times 10000$.

sessed vacuoles containing tubular and lattice myelin and membranous and vesicular material (fig 5).

The number of lamellar bodies was investigated in 20 nucleated cell cross-sections from each of the 24 animals used. There was no significant variation in the number of lamellar bodies per cell cross-section during any period of the light/ dark cycle. Only five lamellar bodies were seen to be open to the alveolar air space in four out of the 480 cell cross-sections studied. However, the abnormal cells were found predominantly during the dark period (fig 7). Out of 72 abnormal cells 48 were from nine out of 10 animals killed during the dark period (2200-0600), 17 abnormal cells were from two out of 10 animals killed during the light period 1000-1800), and seven abnormal cells were fromo two out of four animals killed during the inter-s vening light/dark period (0800 and 2000).

The alveolar type 2 cells all appeared ultra structurally normal. However, cell debris and membrane profiles were seen in the alveolar air $\overrightarrow{0}$ spaces. This would suggest that the above changes $\exists$ in the immersion fixed lungs were not artefacts? induced by the mode of fixation.

\section{Discussion}

This study has shown that the contents of the lamellar bodies of type 2 alveolar cells can be released by exocytosis as described previously. ${ }^{5-}$

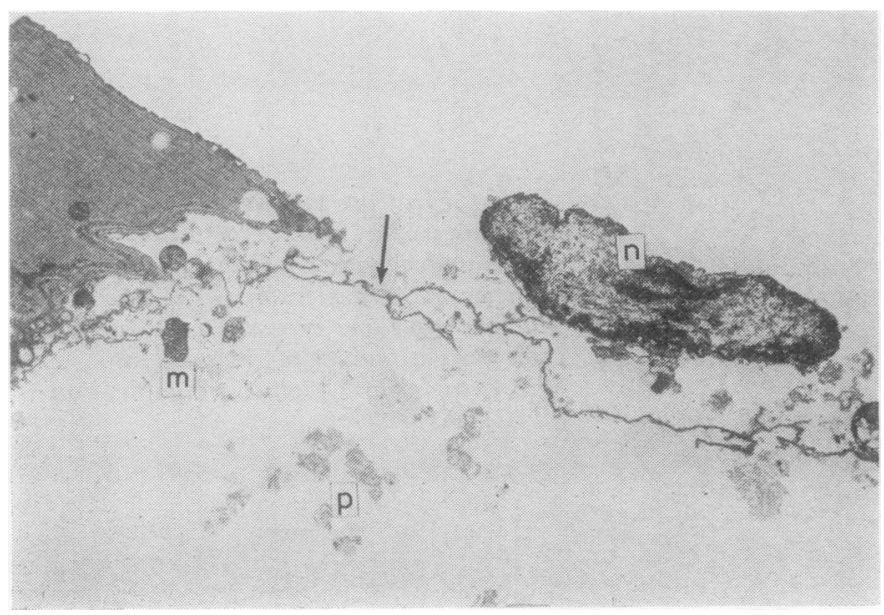

Fig 4 Electron micrograph of an alveolar air space containing remnants of a type 2 cell. The cell membrane (arrow), nucleus (n), degenerate mitochondria $(m)$, and tubular and lattice myelin profiles ( $p)$, can be identified among the debris. Original magnification $\times 6000$. 


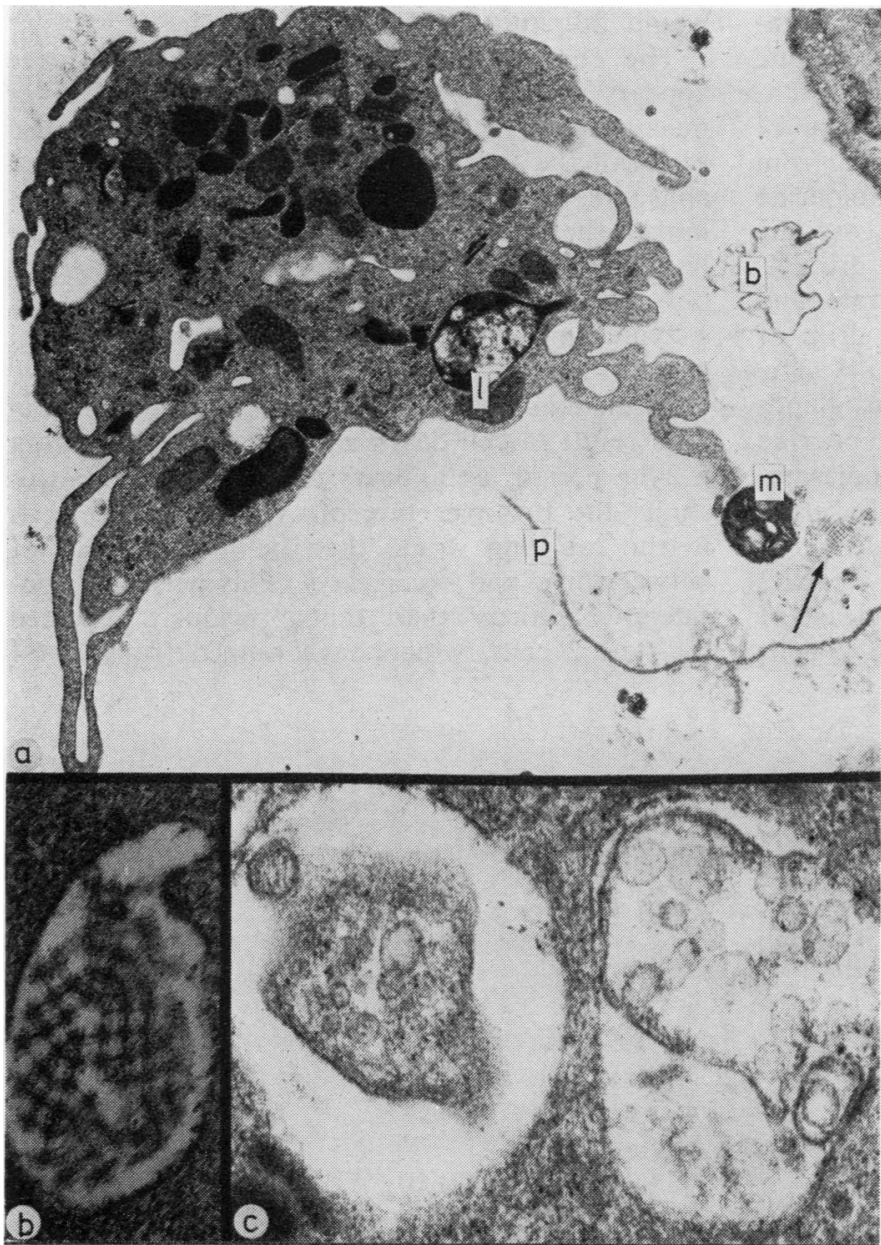

Fig 5 (a) Electron micrograph of an alveolar macrophage possessing a secondary lysosome which contains membranous material $(l)$. Cell debris including cell membrane (p), mitochondria $(m)$, lamellar body (b), and lattice myelin (arrow) lie adjacent to the macrophage. Original magnification $\times 15000$. (b) Electron micrograph of macrophage vacuole containing lattice myelin profile. Original magnification $\times 80000$. (c) Electron micrograph of macrophage vacuoles containing membranous and vesicular material. Original magnification $\times 60000$.

However, this mechanism seems to occur very infrequently in spite of the numerous lamellar bodies observed in each cell cross-section. This suggests that some other mechanism may be involved in the release of lamellar material from type 2 cells. The spectrum of degenerative changes seen in $15 \%$ of the cells and the presence of cell debris in the alveolar air space, may indicate a holocrine secretory mechanism, the lamellar material being released along with the other cell organelles after rupture of the cell. During the initial stages of this process the basal cell membrane is still in contact with the underlying interalveolar septal tissue. Cell debris has been reported previously in the alveolar air space in rats, ${ }^{6}$ and ruptured type 2 cells have been described in alveolar proteinosis in humans. ${ }^{10}$

The possibility exists that these changes are caused by artefact but this appears unlikely for the following reasons. Changes associated with any delay in fixation can be ruled out as Pattle and co-workers ${ }^{11}$ have shown that ultrastructural changes do not occur in type 2 cells within the first 30 minutes after death and even then the changes that do occur are minor. In addition, a general artefact would present itself throughout the $24 \mathrm{hr}$ cycle and not during the dark period. To eliminate any bias the animals were given random numbers and were investigated without any previous knowledge of their place in the cycle. The animal numbers were only crossmatched to the time of day after all the animals had been studied. The unspecific nature of the changes described here conforms to wellestablished patterns in the literature, that irreversible changes involved in cell death occur as a 
result of a combination of defects in ultrastructural organisation rather than any specific lesion.

This proposed mechanism for the release of lamellar material from type 2 cells differs from the commonly quoted example of holocrine secretion, the sebaceous gland. In this case the cell becomes engorged with large lipid droplets while the other cell organelles disintegrate and the entire cell is changed into a huge drop of sebum and which is extruded in toto. ${ }^{12}$ The cellular release of lipids as in the sebaceous glands (holocrine secretion), mammary glands (apocrine secretion), and the adrenal glands (endoplasmocrine secretion) appears in general to be different from the discharge of secretory granules containing proteinaceous material which occurs through the process of exocytosis. The release of the lipid rich lamellar bodies from type 2 cells would fall into the former group.

The cell debris within the alveolar air space appears in part to be removed by the alveolar macrophages. Lysis of the type 2 cells must also $\frac{\bar{D}}{\sigma}$ result in the release of some hydrolytic enzymes, $\unrhd$ and unless these are inactivated or rapidly removed they would damage the remaining alveolar $\vec{\circ}$ lining cells. However, no cellular damage is: observed and it has been postulated that such $\vec{\omega}$ enzymes may be inactivated by selected serum proteins such as $\alpha_{1}$ anti-trypsin. ${ }^{13}$

If the changes observed in the 72 abnormal $\omega$ cells result in cell death and if this occurs within $\omega$ a $24 \mathrm{hr}$ period, as appears to be the case in this $\overrightarrow{0}$ study, the turnover rate of type 2 alveolar cells $N$

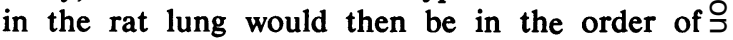
between five and seven days. This period is con- $\overrightarrow{-}$ siderably shorter than that previously reported for type 2 cells, which have ranged from 20-84

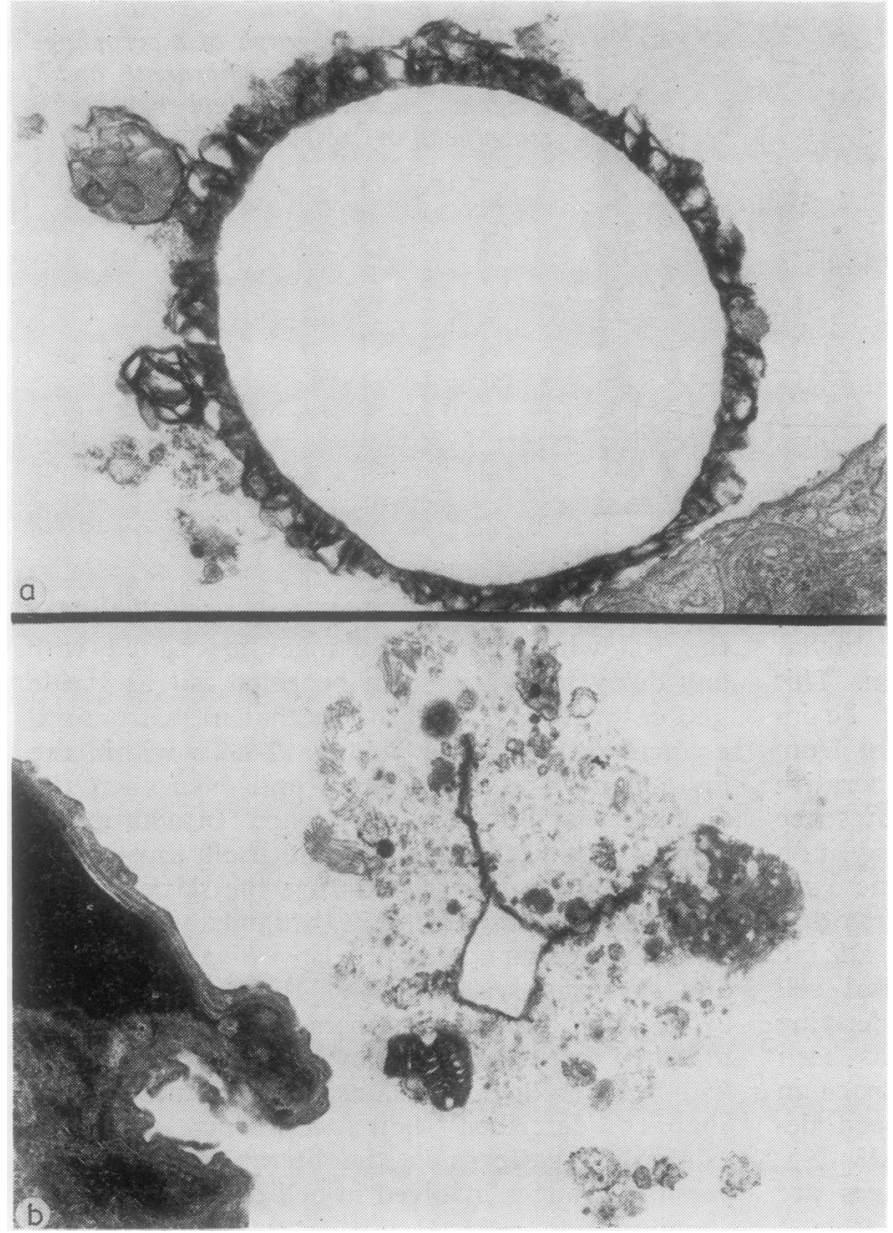

Fig 6 Electron micrographs of membrane profiles found in the alveolar air space. Both examples have their outer surface associated with cell remnants. Original magnifications (a) $\times 30000$, (b) $\times 15000$. 


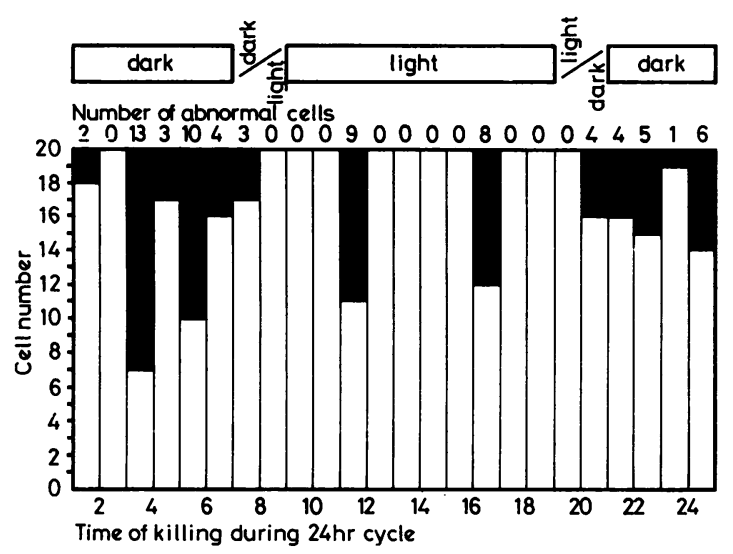

Fig 7 Number of abnormal cells found in 20 nucleated cell cross-sections counted in each of the 24 animals killed in pairs during the $12 \mathrm{hr}$ dark $/ 12 \mathrm{hr}$ light cycle. The aberrant cells are found predominantly during the dark period. The aberrant cells are shown black on the histogram.

days. 14-16 Evans and Bils ${ }^{16}$ showed that, after division of type 2 cells, one of the daughter cells remains in the tissue and the other leaves the area. The fate of the latter cell was not determined. The holocrine secretory mechanism proposed in this communication may be a possible route by which the daughter cell is eliminated, so leaving a static population of type 2 cells. However, adjacent type 2 cells were seen only rarely and on these occasions the cells were both ultrastructurally normal.

The appearance of the degenerate type 2 cells suggests a possible holocrine secretory mechanism occurring predominantly during the dark period when the rats are active. This reason may account for this previously unsuspected mode of release of the lamellar bodies from the type 2 alveolar cells as it occurs when most scientists are asleep.

I would like to thank Mr RJ Hill, Mrs J Hoy, and Miss D Symons for their valuable technical assistance, and Mrs RE Hill for her secretarial help.

\section{References}

1 Askin FB, Kuhn C. The cellular origin of pulmonary surfactant. Lab Invest 1971; 25:260-8.

2 Hoffman L. Isolation of inclusion bodies from rabbit lung parenchyma. J Cell Physiol 1972; 79: 65-72.

3 Gil J, Reiss OK. Isolation and characterisation of lamellar bodies and tubular myelin from rat lung homogenates. J Cell Biol 1973; 58:152-71.

4 Kikkawa Y, Yoneda K, Smith F, Packard B, Suzuki K. The type II epithelial cells of the lung. II. Chemical composition and phospholipid synthesis. Lab Invest 1975; 32:295-302.

5 Bensch K, Schaefer K, Avery ME. Granular pneumocytes: electron microscopic evidence of their exocrinic function. Science 1964; 145: 1318-9.

6 Leeson TS, Leeson CR. Osmiophilic lamellated bodies and associated material in lung alveolar spaces. J Cell Biol 1966; 28:577-81.

7 Sorokin SP. A morphologic and cytochemical study on the great alveolar cell. J Histochem Cytochem 1967; 14:884-97.

8 Ryan US, Ryan JW, Smith DS. Alveolar type II cells: studies on the mode of release of lamellar bodies. Tissue Cell 1975; 7:587-99.

9 Brody AR, Craighead JE. A simple perfusion apparatus for lung fixation. Proc Soc Exp Biol Med 1973; 143:388-9.

10 Schober R, Bensch KG, Kosek JC, Northway WH. On the origin of the membranous intraalveolar material in pulmonary alveolar proteinosis. Exp Mol Pathol 1974; 21:246-58.

11 Pattle RE, Schock C, Creasey JM. Post-mortem changes at electron microscope level in the type II cells of the lung. Br J Exp Pathol 1974; 55: 221-7.

12 Rhodin AG. Histology: a text and atlas. New York: Oxford University Press, 1974: 90.

13 Hook GER, Bell DY, Gilmore LB, Nadeau D, Reasor MJ, Talley FA. Composition of bronchoalveolar lavage effluents from patients with pulmonary alveolar proteinosis. Lab Invest 1978; 39:342-57.

14 Bertalanffy FD, Leblond CP. The continuous renewal of the two types of alveolar cells in the lung of the rat. Anat Rec 1953; 115:515-24.

15 Simnett JD, Heppleston AG. Cell renewal in the mouse lung. Lab Invest 1966; 15:1793-1801.

16 Evans MJ, Bils RF. Identification of cells labeled with tritriated thymidine in the pulmonary alveolar walls of the mouse. Am Rev Respir Dis 1969; 100:372-8. 